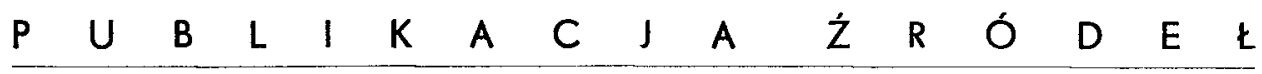

A r c h 1 wa, B 1 bliotekl

1 Muzea Kościelne. Tom 17

\title{
DOKUMENTY FUNDACYJNE DIECEZJI SMOLEŃSKIEJ
}

\author{
WYDAE KS. BOLESEAW KUMOR
}

Ostatnie dwie fundacje diecezji obrządku łacińskiego przez królów polskich w przedrozbiorowej Rzeczypospolitej miały miejsce pod koniec XVI i w pierwszej połowie XVII stulecia. Pierwsza z nich, diecezja wendeńska, została utworzona w latach 1582/83 dla zdobytych Inflant 1 , druga natomiast, diecezja smoleńska, została zorganizowana ostatecznie dopiero w $1636 \mathrm{r}$. Na podstawie rozejmu dywilińskiego (11 XII 1618), zawartego z Rosją, zostały przyłączone do Rzeczypospolitej ziemie: smoleńska, czernichowska i siewierska. Dla tych zdobytych terenów Zygmunt III Waza postanowił ufundować biskupstwo smoleńskie wkrótce po r. 1613. Pierwszym administratorem tworzącej się diecezji był w 1617 r. ks. M. Siwicki ${ }^{2}$. W czasie procesu apostolskiego, w związku z erekcją diecezji, ks. Piotr Parczewski, nominat Wladysława IV na biskupstwo smoleńskie, zeznał 24 IX 1635, ze ,fundacja biskupstwa smoleńskiego - - była wszczęta jeszcze przèz Zygmunta, króla Polski, ale $z$ powodu prowadzonych wojen została zaniechana" ${ }^{3}$.

Tymczasem ta ,istnie jąca" diecezja az do 1625 r. nie posiadała zupełnie podstaw prawnych, zarówno bowiem król polski, do którego należało uposazenie nowej diecezji, jak i Stolica Apostolska, której wyłącznıe przysługiwało prawo erygowania jej, nie poczynili żadnych kroków w tym celu. Główną przyczynę takiego stanu rzeczy mozna wıdzieć $\mathrm{m}$. in. w następujących czynnikach:

1) Nowozdobyte ziemie posiadały statut tymczasowej przynależności politycznej do Rzeczypospolitej; zostały one bowiem wcielone nie na podstawie układu pokojowego, ale tylko na skutek rozejmu.

2) Fundacja nowej diecezji łacińskiej związana była ściśle $z$ powiększeniem iloścı senatorów $\mathrm{w}$ sejmie polskim; kazdy bowiem biskup ordynariusz obrządku łacińskiego wchodził do senatu. Tymczasem król nie mógł samowolnie powiększać liczby senatorów, ale musiał na to posiadać zgodę sejmu ${ }^{4}$.

Te tez czynniki zaważyły na tym, ze dopiero $6 \mathrm{~V} 1625$ Zygmunt III Waza wystawił dokument fundacyjny dla biskupstwa $i$ kapituły katedralnej ${ }^{5}$. Ale i tym razem postanowienie królewskie nie zostało wprowadzone w życie. Wydaje się, że równiez wtedy główną przeszkodą był tymczasowy charakter

\footnotetext{
1 Por. E. Kuntze: Utworzenie biskupstwa wendeńskiego przez Stefana Batorego. W. Studia historyczne ku czcı St. Kutrzeby. T. 2. Kraków 1938 s. 443-467.

$2 \mathrm{Ks}, \mathrm{T}$. Długosz: Dzıje diecezji smoleńskiej. Lwów 1937 s. 13.

3 Ks. B, K u m or Granıce metropolii gnıénıeńskiej 1 jej sufraganii w okresıe przedrozbiorowym. Rocz-2 teol.-kanon. T. 13: 1966 z. 4 s. 57.

4 Ks. T: D I g o sz, Jw s. 5, 30.

5 Zob. dokument nr 1.
} 
przynalezności Smoleńszczyzny do Polski i rozpoczynające się wojny polsko-szwedzkie. $261 \times 1629$ doszło do zawarcia rozejmu altmarskiego ze Szwecją, a 14 VI 1634, po nowej zwycięskiej wojnie, został podpisany w Polanowie wieczysty pokój z Rosją. Pokój ten potwierdził w całej rozciągłości warunki rozejmu dywilińskiego, a nadto pozostawił w granicach Rzeczypospolitej okręg Trubecka.

Teraz dopiero nowy król polski, Władysław IV, przystąpil do realizacji postanowień swego ojca, Zygmunta III Wazy, dotyczących utworzenia diecezji w Smoleńsku. Aktem z 28 IV 1635 ponowił on fundacje biskupstwa i kapituły katedralnej $w$ Smolensku przy kościele Zwiastowania NMP ${ }^{6}$. Wkrótce potem, bo juz 28 VIII 1635, papież Urban VIII polecił rozpoczęcie procesu kanonicznego w sprawie erekcji diecezji. Po jego pomyślnym zakończeniu tenze papiez, na konsystorzu tajnym 1 IX 1636, dokonał kanonicznej erekcji biskupstwa, zastrzegając prawa patronatu dla królów polskich 7 .

W chwili przeprowadzania procesu apostolskiego sam Smoleńsk liczył około 5 tysięcy mieszkańców i miał być zależny pod względem jurysdykcyjnym bezpośrednio od nuncjatury papieskiej w Warszawie. Ze względu na ,istniejącą" od kilkunastu lat diecezję była tam również szczątkowa kapituła katedralna, złożona $z$ archidiakona i dwóch kanoników ${ }^{8}$.

Publikowane niżej dwa dokumenty fundacyjne biskupstwa smoleńskiego znajdują się $w$ formie współczesnych kopii $w$ aktach procesu informacyjnego w sprawie erekcji tejże diecezji. Wydawcy znane są dwie kopie obydwu dokumentów; przy czym odpis $\mathrm{z}$ akt procesu informacyjnego, przechowywanego w Archiwum Kongregacji Konsystorialnej, jest czystopisem, podczas gdy kopia druga, $z$ akt procesu, zachowanego w Archiwum Datarii Apostolskiej, posiada charakter brulionu. Tekst obydwu dokumentów jest w licznych partiach identyczny. Nie jest to jednakże dosłowne powtórzenie.

Dokument bowiem Władysława IV posiada pewne istotne dodatki. Fundacja z $1625 \mathrm{r}$. wymieniała w granicach diecezji ziemie: smoleńską, siewierską i czernichowską, podczas gdy dokument z $1635 \mathrm{r}$. - tylko smoleńską i siewierską. Ta ostatnia nawet nie została w całości pod jurysdykcją biskupa smoleńskiego, albowiem konstytucja sejmowa $z 1638$ r. podporządkowala powiat Nowogród Siewierski i całe województwa czernichowskie diecezji kijowskiej ${ }^{9}$. Dokument Władysława IV zawiera również nominację królewską na biskupstwo smoleńskie w osobie ks. Piotra Parczewskiego. Wreszcie dalszym, ważnym postanowieniem przywileju Władysława IV jest włączenie utworzonej diecezji do metropolii gnieźnieńskiej. Zgodnie z tym ostatnim postanowieniem w r. 1643 wziął udział w synodzie prowincjalnym gnieźnieńskim pierwszy biskup smoleński Piotr Parczewski i reprezentant tamtejszej kapituły ks. Jan Rowiński ${ }^{10}$. Szereg dalszych róznic między obydwoma doku. mentami zachodzi na odcinku uposazenia biskupstwa i kapituly katedralnej. Tak w 1625 r. było wydzielonych tylko 400 łanów, zwanych Ujsok, dla

i Zob. dokument nr 2.

P G a u ch a t: Hierarchıa catholica medii et recentiorıs aevı. T. 4 (1592-1667). Monasterii 1935 s. 318 (,In consistorio secreto, kalendas septembris 1636 habito, Ssmus D.N. erexit ecclesiam Annuntiationis BMV oppidi Smolensk, in Magno Ducatu Lithuanıae, ritus Latin in cathedralem idemque oppidum in civitatem episcopalem cum reservatione jurispatronatus regis Poloniae").

8 Tamze; por, BAV. Proces. Consist, Vol. $35 \mathrm{k}, 333^{\prime} \mathrm{nn}$.

3 Ks. B. K u m o r, jw. S. 57.

10 Synodus provincıalis Gnesnensıs provınciae sub R.D. Mathıa Eubıeńskı archıep. Gnesnen. Varsaviae anno Domini 1643, 8 XI celebrata. Varsaviae 1646 5. 8 nlb. 
biskupstwa, natomiast dla kapituły nie były jeszcze wyznaczone place w Smoleńsku pod budowę domów. W 1635 r., z 2500 łanów, biskup nie miał jeszcze wymierzonych 700 , a kapituła - 500 na dystrybucje i 100 łanów na ogrody. W dokumencie z 1635 r. pominięto szereg zastrzezeń, wysuniętych przez Zygmunta III w 1625 r. odnośnie zabudowy Smoleńska poza murami miasta i wokół kościoła św. Ducha poza miastem. Podczas gdy dokument pierwszy nadawał przywilej na dwudniowe jarmarki w okresie Zielonych Swiąt, to dokument drugi rozciągnął go na cały tydzień. Fundacja Władysława IV uzupełniła też wykaz nabozeństw dziękczynnych, które miala odprawiać kapituła smoleńska. Do rocznicy zdobycia Smoleńska, wypadającej na 13 czerwca (św. Antoniego z Padwy), Władysław IV dodał nadto dwie nowe - w dniach 29 września (św. Michała) i 24 lutego (św. Macieja).

Obydwa dokumenty fundacyjne były znane historiografii polskiej, dzięki rozprawie ks. Teofila Dlugosza (Dzieje diecezji smoleńskiej), ale dotąd nie zostały wydrukowane. Publikacja tych dokumentów została przygotowana do druku zgodnie z Instrukcja wydawnzcza dla źródeł historycznych od XVI do połowy XIX wieku (Wrocław 1953).

\section{DOKUMENTY}

\section{Nr 1 - Dokument fundacyjny Zygmunta III Wazy}

Warszawa, $6 \mathrm{~V} 1625$

Zygmunt III Waza, król polski $i$ szwedzki, w podziękowaniu Bogu za szczęśliwe odzyskanie Smoleńska i innych prowincji, oderwanych niegdyś przez Rosje od Litwy, funduje biskupstwo smoleńskie. Terytorium nowej diecezji, według postanowień króla, ma objać Ziemie Smoleńska, Siewierska i Czernichowska. Na katedrę biskupia wyznacza król świętynię pod wezwaniem Zwiastowania NMP $w$ Smoleńsku. Równocześnie król uposaża biskupstwo $i$ kapitule katedralna $w$ dobra ziemskie $w$ województwie smoleńskim. Kapitula ma się składać z 6 prałatur (prepozyt, dziekan, archidiakon, kustosz, scholastyk $i$ kantor) $i 12$ kanonii gremialnych. Prawa prezenty $i$ patronatu do nowoutworzonych beneficjów kościelnych rezerwuje król dla siebie $i$ swoich następców, z wyjątkiem czterech miesięcy (luty, kwiecień, październik, grudzieñ), które zastrzega dla biskupa smoleñskiego. Temu ostatniemu przyznaje król, za zgoda sejmu, miejsce $w$ senacie.

Or. nie znany.

Kopie: 1. BAV (Bibliotheca Apostolica Vaticana). Processus Consist. Vol. $35 \mathrm{k}$. 316-369: Processus fundation is seu erectionis oppidum Smolensk in episcopatum illiusque ecclesiam BMV Annuntiationis cathedralem una cum 6 dignitatibus et 12 canonicatibus 1635 k. 318-323'; 2 Processus Dotariae. Vol. 14 k. 460-521: Ecclesiae Smolenscensis erectio $1635 k$. 467-471.

Sigismundus Tertius, Dei gratia rex Poloniae, magnus dux Lithuaniae" ${ }^{11}$ etc., significamus praesentibus literis nostris, quorum interest universis et singulis. Omnium gentium animis moribusque insitum esse a natura, ut divinitatis opinionem in magnorum meritorum nominibus, aut rebus quibusdam publicae privataeque religionis, aut admirationis speciem adeptis, sequantur. Et quamvis hic a veri Numinis saepe notitia cultuque decepta mortalium studia aberraverint, non tamen errori, aut superstitioni opes, vel fiducia defuere, quin fulgorem et venerationem

11 Zygmunt III Waza, król polsk (1587-1632) थ szwedzki (1592-1604 detr.). 
verae falsaeque sanctitatis famae tribuerent. Hinc aris initium, hine simulacris statuisque prima incrementa, donec se ad templorum etiam audaciam erexit humani obsequii promptitudo opulentiaque. Nec singulorum modo hominum, aut civitatum nationumve hic erga divini honoris aestimationis domi consensus ac diligentia fuit, sed multorum etiam populorum aemulatio limites fascesque suos egressa, ad communis templi constructionem sumptus alio extulit, concurrentibus certantibusque undique expensis ad magnae et illustris celebritatis sedem religioni circumdandam. Cum locorum honoribus, aucta etiam maiestas eorum, qui rem divinam procurabunt, quantoque clarius et magnificentius delubrum, tanto etiam antistitum dignitas maior augustiorque, sed et horum saepe sanctitas templorum fortunas splendoremque accepit et sacris non raro a praesule claritudo gloriaque venit. Nec enim postremum locorum decus et prosperitas est in boni rectoris curam et sollicitudinem incidisse, sed praecipua potius maximaque securitatis pars censeri debet foelici et matura regi prudentia, quae pro divini cultus sinceritate et conservatione, perpetua vigilantia, officium et sanctimonia excubet, quae si ubique utilitate ipsa et successibus suis commendatur, illis sane maiore apparatu et necessitate exeguntur, ubi propinquius multarum rerum tempestatumque terror, facile periculum, et iniuriam aut denique exitium religioni pietatique comminatur.

Nos itaque, cum miseratione et singulari benedictione arcem nostram Smolenscum ${ }^{12}$ caeterasque provincias nostras, iniquissime ab hoste nostro Moscho sub tempus pactorum et perpetui foederis raptas, primum quidem nostro sub Smolenscum, deinde vero serenissimi principis Wladislai, filii nostri charissimi ${ }^{13}$, sub metropolim Moscoviae expeditione, et felici utriusque nostrum periculo, recuperavimus Magnoque Ducatui Lithuaniae, a quo avulsae erant, restituerimus. Postquam pro situ et patientia locorum res componere et stabilire licuit, omni quoque, qua licet, animi gratitudine divini erga nos beneficii memoriam respicere atque venerari et imposterum testari publice constituimus. Muneri enim vicissim debitoque nostro consentaneum existimavimus, non prius alicubi ditiones nostras, quam Dei optimi, maximi honorem, veraeque religinis integritatem incipere. Nam in his una verague felicitas, omnis vis et salubritas constat, quippe cum quibus Deus ipse in sincera sui adoratione ad actionum rerumque omnium aspicia et successus praesentis et faventis Numinis benevolentia adest.

Quamobrem, ut sacris honos et sinceritas sua illic restituatur, ubi provincia Magno Ducatui Lituaniae principique suo restituta est, eam non a barbarae tantum crudelitatis iugo, sed a corrupta religionis noxa vindicasse in gloria et felicitate nostra etiam ducere voluimus. Cuius rei cum maximum in eo sit momentum, ut legitime et rite constituto regimine sacrorum munerum iura, sacraeque doctrinae progressus et caeremoniarum ritus disciplinaque ex ecclesiae et canonum praescripto instituantur et gubernentur.

Ideo, ut haec omnia censere perfecteque in Smolenscensi provincia instaurari possint, neve illa posthac ad remoti pastoris curam et longinqua praesidia exire, aut distrahi cogatur, laudatis maiorum nostrorum aliorumque principum piorum vestigiis insistentes, singularem dioecesim et episcopatum in praefatis provinciis, sub titulo et appellatione Smolenscensis, fundandum erigendumque, et proprium ac peculiarem episcopum, metropolitae tamen et primati Regni subordinatum, dandum et assignandum duximus, prout divino in primis invocato nomine, de Sanctae Sedis Apostolicae consensu et approbatione minime ambigentes, praesentibus insti-

${ }_{12}$ Smolénsk, miasto obwodowe $w$ zachodniej części Rosyjsłıej Repubilki Radzieckiej, potozony nad Dneprem. W latach 1386-1514 i 1611-1654 nalezat do Polskt. W $r$. 1667, na podstauie rozejmu andruszowskiego, zostai oddany Rosji, co potwıerdzono príniej w połoju Grzymuttowskiego (1686).

13 Wtadysław IV Waza, król polski (1632-1648). 
tuimus, erigimus et fundamus elque regimen totius cleri in ducatibus Smolenscensi, Czerniehoviensi ${ }^{14}$ Severiensique ${ }^{41 a}$ existentis et deinceps futuri, iuxta iura canonica et consuetudines S.R.E. longo usu probatas, in perpetuum committimus. Et inprimis antiquissimam ecclesiam muratam tituli Annuntiatae Virginis Mariae, modo quidem desertam, sed olim a praedecessoribus nostris piae extructam, intra muros Smolenscenses, in monte Przecisciessoka, alias Dziedziniec dicto, sitam, pro ecclesia cathedrali designamus, ibidemque in monte pro resicientia episcopali domum veterem muratam, nominatae ecclesiae contiguuam, cum suficicienti pr,o aula et pomario episcopalibus capacitate, area quoque pro comibus praelatorum, canonicorum aliorumque presbiterorum per praefectum nostrum praesentem Smolenscensem a civitate Smolenscensi, eiusdem montis partem occupante, dislimitandas assignamus, ita tamen, ut areas sive domus cuusque praelati et canonici intra muros longitudinem octoginta, latitudinem vero quadraginta ulnarum non excedat, aream vero pro horto episcopi extra muros, ita tamen ut in eo horto nulla domus condatur, nec ullus ullo praetextu maneat, aut civitati nostrae Smolenscensi intra muros fundatae ordinem et mercaturas impediat. Iiem alteram ecclesiam muratam tituli S. Spiritus, similiter a praedecessoribus nostris extructam, ad praesens desertam extra muros Smolescenses, ad Boristenem ${ }^{15}$ sitam, ubi Moscus erat castrametatus, cum caemeterio eandem ecclesiam circumdante, assignamus, quam ecclesiam episcopus restaurare, divinaque missae officia diebus festis iuxta arbitrium et dispositionem propriam celebranda procurabit. Hoc tamen praecavemus, ne circa nominatam ecclesiam ulla domus erigatur, nec quisquam ibi respectu aliquo aedificia condat, idque ob quaedam impedimenta et respectus civium intra muros Smolenscenses residentium.

Nundinas demum mercatoribus et civibus circa eandem ecclesiam fieri mercimoniaque libere exercere pro festo Pentecostes per biduum concedimus, ut praefectus noster Smolenscensis ad praesens ex vi huiusce privilegii disponet et designabit. Porro, ut episcopi Smolenscenses pro tempore existentes in statu suo praesulari honeste et convenienter vivere, et sufficientem muneri suo familiam alere, aliaque cathedralis ecclesiae onera, episcopis de more et consuetudine incumbentia, substinere possint, eidem episcopatui Smolenscensi ad usum fructum episcoporum Smolenscensium bona certa in ditione palatinatus Smolenscensis Malachoviense sita ${ }^{16}$, $\mathrm{Vujsock}$ nuncupata ${ }^{17}$, per geometram nostrum iuratum in quadringentos laneos, alias $\mathrm{mlok}$, redacta et dislimitata. Alia item bona in ditione palatinatus Smolenscensis $\mathrm{K}$ a t $\mathrm{yn}^{18}$ et Bereznensi ${ }^{18}$ a sita, vetus castellum $\mathrm{Olsz}$ a $\mathrm{nko}{ }^{19}$, cum agris contiguuis in quadringentos itidem laneos redacta, sigillatim vero ditione eiusdem palatinatus Smolenscensis Dołhomoscense ${ }^{20}$ laneos ducentos per praefectum nostrum praesentem Smolenscensem designandos et dislimitandos. In capitaneatu praeterea

14 Czernihów, masto obwodowe $w$ pótnocnej częśc Ukrainy Radzıeckiej, na prawym brzegu Desny. Od 1386-1504 a 1618-1654 nalezat do Polskı. W r. 1654 na mocy ugody perejestawskiej zostat oddany Rosji.

${ }^{14}$ a Siewierz, Siewierszczyzna, Ziemza Siewierska - nazwa radawana dawnej dorzeczu

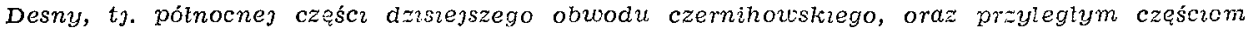
obwodu mohylowskiego, homelskiego z brińskiego.

15 Boristenes, nazwa kačńsła dla rzek Dnepr.

1t Malachow, miejscowość $w$ Snoleńskiem, bliżej nie zadentyfikouiana.

17 Wujsok, bliżej ne zldentyfikowany; moze Wojpity, na poludnowy wschód od Mohylowa, nad Dneprem.

18 Katyń, osada na zachód od Smoleńska, przy drodze smoleńsk - Witebsk.

${ }^{18}$ a Berezına W. i Berezina M., miejscowośc na wschód od Dobromyśla $\imath$ Babınowicz, obwód smoleństi.

19 Otszanko zamek, $w$ daunym wojew. smoteńskim.

z Dorohobuz, miasto na lewym brzegu górnego Dnıepru, obwód smoleńsłı. 
nostro Eielscensi ${ }^{21}$ laneos quingentos per praefectum itidem nostrum Smolenscensem designandos $e_{i}$ dislimitandos. Denique in capitaneatu nostro Starodubensi ${ }^{22}$ vetus castellum, Popow a Gor a ${ }^{22 a}$ nuncupatum, mille laneis agrorum et silvarum propius adiacentium, per geometram nostrum iuratum, scitu tamen et designatione praefecti nostri praesentis Smolenscensis, limitandum in perpetuum applicamus et irrevocabiliter in aevum appropriamus.

Porro, ut cultus divini, quem nos apprime desideramus, gravior sit maiestas et amplitudo, ad eandem ecclesiam cathedralem Smolenscensem sex praelatos, praepositum videlicet, decanum, archidiaconum, custodem, scholasticum et cantorem, canonicos insuper, duodecim, eos vero tantum nobili ortos genere, vel etiam doctores, in perpetuum instituimus et designamus. Episcopus autem in id maxime incumbet, ut numerus aderuatus canonicorum, ne scilicet beneficia specilicata longo intervallo temporis vacent, successive expleatur; pro quorum sustentatione et vicariorum (quos canonici quilibet suum habere tenebuntur), tum scholae et musicorum ecclesiasticorum provisione in ditione palatinatus Smolenscensis Boyhorodensi ${ }^{23}$ laneos mille per praefectum nostrum, praesentem Smolenscensem, designandos et tradendos, per geometram vero nostrum mensurandos et dislimitandos, assignamus et in perpetuum capitulo Smolenscensi incorporamus. Ita tamen, ut ex laneis praedictis centum lanei cedant praeposito Smolenscensi, octuaginta lanei decano, archidiacono octuaginta, custodi itidem octuaginta, scholastico lanei sexaginta, cantori sexaginta, caeteris vero duodecim canonicis lanei quingenti, cantoribus et custodibus ecclesiasticis lanei quadraginta. Insuper toti capitulo Smolenscensi silvae laneos centum in eadem ditione Boyhorodensi; in capitaneatu vero Bielscensi laneos quingentos per praefectum nostrum Smolenscensem designandos, per geometram vero nostrum iuratum limitandos, perpetuis temporibus impertimur. Denique eidem capitulo Smolenscensi ad maiorem eorum commoditatem et residendi assiduitatem et studium cathedralis ecclesiae in eis excitandum pro hortis et priediolis prealatorum et canonicorum post agros, sive pascua civitatis nostrae Smolenscensis laneos centum per succamerarium seu commissarios nostros designandos et limitandos perenniter donamus, eaque omnia bona suprascripta, tam episcopatui, quam capitulo Smolenscensi a nobis in perpetuum donata et incorporata, libertatibus et immunitatibus S.R.E. adscribimus, ita tamen, ut iuri quoque communi Magni Ducatus Lituaniae, iudiciis ordinariis in tribunali vero iudicio composito, subsint, prout aliarum quque ecclesiarum in Magno Ducata Lituaniae existentium possesiones subsunt, iuribus tamen S.R.E. salvis. Caeterum proventus bonorum capituli, quid cuique sit pendendum, aut quae bona cuique praelatorum et canonicorum sint tradenda, primus episcopus Smolenscensis ex consilio capituli ordinabit et decernet.

Collationem porro et iuspatronatus, tam episcopatus Smolenscensis, quam et praelaturarum et canonicatuum Smolenscensium, nobismetipsis et successoribus nostris, serenissimis regibus Poloniae et magnis ducibus Lituaniae, reservamus. Ut nihilominus episcopus quoque Smolenscensis maiori apud clerum authoritate valeat et studiosius observetur, excipimus quatuor anni menses, februarium, aprilem, octobrem et decembrem, quibus, si quem praelatorum aut canonicorum Smo-

21 Biala, dawny powat w wojew. smoleńskim, obecnie Biełyj we wschodniej częscr oowodu Wielkie Łuki.

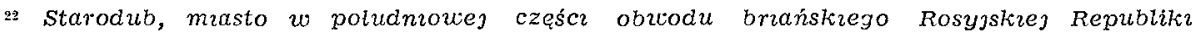
Radzieckiej.

"a Popoua Góra, stary zamek $w$ starostuie starodubeckım, wojew. smoleñskim, na poinocny zachód od Staroduba.

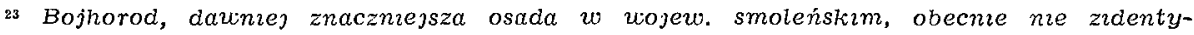
fikowana. 
lenscensium de vita excedere contigerit, vacantes sub nominatis quatour mensibus praelaturas et canonias ipsemet episcopus Smolenscensis clericis integritate et coctrina conspicuis, et de Sancta Ecclesı bene meritis, nostro et successorum nostrorum iurispatronatu non obstante, pro libitu et voluntate sus, praesentis privilegii nostri vigore, conferre valebit. Eacue designatis quatuor mensibus praerogativa, a nobis benigne concessa, episcopı Smolenscenses in perpetuum utentur et gaudebunt. Caeter,um bona praefata omnia, tam episcopi Smolenscenses sua, unus post alium, quam praelati et canonici itidem sua, sibi a nobis in perpetuum data et donata, tam domos in civitate Smolenscensi, tam alia quoque possesiones terrestres, modo suprascripto limitatas et limitandas, cum omnibus subditis praesentibus et in posterum futuris, eorumque censibus et regimine, cum agris, pratis, silvis, nemoribus, fluviis, lacubus, stagnis, piscationibus, venationibus, melificiis, caeterisque omnibus usibus, fructibus et quibuscumque redditibus intra limites superus designatos, contentis et in posterum inveniendis, pacifice tenebunt, possidebunt et iuxta praescriptum S.R.E. perpetuis temporibus uti fruentur, omnibusque praerogativis, honoribus et praeeminentiis, episcopi vero Smolenscenses loco etiam in senatu nostro, ex consensu publico designando, potientur et gaudebunt.

Demum obligamus eosdem, ut circa ecclesiam cathedralem Smolenscensem residere, pro nobis et serenissimis successoribus nostris ac tota Republica nostra Deum optimum, maximum exorare teneantur. Omnimodam deinde devotionem ac caeremonias iuxta ordinem, consuetudinem dispositionemque ecclesiae cathedralis Vilnensis servare, matutinaque et horas canonicas, tam ante meridianas, quam post meridianas, prout disponet cum capitulo episcopus, cantare tenebuntur, divinumque honorem omni conatu et studio promovere obligabuntur. Praeterea in perpetuum ex vi huiusce privilegii nostri episcopi Smolenscenses pro festo s. Antonii de Padua ${ }^{24}$, die quo divina miseratione Smolenscum per nos ab hoste est receptum, in perennem gratiarum actionem et vivam praeclari divini beneficii memoriam, quod nobis et Reipublicae nostrae in recuperatione per nos ducatuum nostrorum Smolenscensis, Severiensis Czerniehoviensisque collatum submissae profitemur, processiones et supplicationes publicas instituere et quantas potest humana infirmitas grates referre. Insuper quovis anni mense seme1, ut minimum in elusdem beneficii memoriam tenebuntur episcopi Smolenscenses per se, sive per aliquem praelatorum, gratissimo et solemni missae officio sacrosanctam et vivificam hostiam supremo Trinoque Numini parentare, et praecari, ut eas provincias, quas nobis et Reipublicae nostrae benigne restituit, clementer tueri et manu sua potent1 dignetur ab hoste defender,e verumque et inviolatum sui in eis cultum quam diutissime conservare.

Quae quidem omnia vim perpetuitatis obtinere volentes, praesentes manu nostra subscripsimus sigilloque nostro Magni Ducatus Lituaniae obsignari mandavimus. Datum Varsaviae die 6 mensis maii anno Domini 1625, regnorum nostrorum Poloniae 38, Suetiae 31.

\section{Nr 2 :- Dokument fundacyjny Wtadystawa IV}

Warszawa, 28 IV 1635

Wladysław IV Waza, król polski, w podzięce Bogu za zwycięskie zakończenie wojny z Rosja ponawia fundację biskupstwa smoleńskiego. Diecezja, która administruje tymczasowo ks. Piotr Parczewski, będzie należała do metropolii gnieźnieńskiej, granice zaś jej maja objać tylko Ziemię Smoleńska

24 Smolensi zostat zdobyty przez wojska polskıe $13 \mathrm{VI} 1611$ (13 VI - św. Antoniego z Padwy). 
i Siewierska. Na katedrę biskupia przeznacza on świętynię pod wezwaniem Zwiastowania NMP w Smoleńsku, Na uposażenie biskupstwa oddaje król pewne dobra ziemskie $w$ województwie smoleńskim. Równocześnie uposaża on kapitute katedralna, która będzie się składała $z$ pratatów (prepozyt, dzzekan, archidiakon, kustosz, scholastyk, kantor) $i 12$ kanoników gremialnych. Prawa prezenty $i$ patronatu na nowe beneficia kościelne rezerwuje król dla siebie $i$ swoich następców, $z$ wyjątkiem czterech miesięcy $w$ roku (luty, kwiecień, październik i grudzień), kiedy to maja one przystugiwać biskupowi smoleńskiemu. Za zgoda sejmu przyznaje król nadto biskupom smoleńskim miejsce $w$ senacie.

Or. nie znany.

Kopie: 1. BAV. Processus Consit. Vol. $35 \mathrm{k}, 316-369$ : Processus fundationis seu erectionis oppidi (Smolenssk in episcopatum - - 1635 k. 323'-329; 2. Processus Datariae. Vol. 14 k. 460-521: Ecclesiae Smolenscensis erectio 1635 k. 462-466.

Wladislaus Quartus, Dei gratia rex Poloniae, magnus dux Lituaniae ${ }^{25}$ etc. Significamus praesentibus literis nostris, quorum interest universis et singulis. Omnium gentium animis moribusque insitum a natura esse, ut divinitatis opinionem in magnorum meritorum nominibus, aut rebus quibusdam publicae privataeque religionis, aut admirationis speciem adeptis, sequantur. Et quamvis hic a veri Numinis saepe notitia cultuque decepta mortalium studia aberraverint, non tamen errori, aut superstilioni opes, vel fiducia defuere, quin fulgorem et venerationem verae falsaeque sanctitatis famae tribuerent. Hinc aris initium, hinc simulacris statuisque prima incrementa, donec se ad templorum etiam audatiam erexit humani obsequii promptitudo opulentiacue. Nec singulorum modo hominum, aut civitatum nationumve, hic erga divini honoris aestimationis domi consensus ac diligentia fuit, sed multorum etiam populorum aemulatio limites fascesque suos egressa ad communi templi constructionem sumptus alio extulit, concurrentibus certantibusque undique expensis ad magnae et illustris celebritatis sedem religioni circumdatam. Cum locorum honoribus, aucta etiam maiestas eorum, qui rem divinam procurabunt, quantoque clarius et magnificentius delubrum, tanto etiam antistitum dignitas maior illustriorque, sed et horum saepe sanctitas templorum fortınas splendoremque accepit et sacris non raro a praesule claritudo gloriaque venit. Nec enim postremum locorum decus et prosperitas est in boni rector,is curam et sollicitudinem incidisse, sed praecipua potius maximaque securitatis pars censeri debet felici a matura regi prudentia, quae pro divini cultus sinceritate et conservatione, perpetua vigilantia officium et sanctimonia excubet, quae si ubique utilitate ipsa et successibus suis commendatur, illis sane maiore cum apparatu et necessitate exeguntur ubi propinquis multarum rerum tempestaturamque terror, facile periculum et iniuriam, aut denique exitium religioni pietatique comminatur.

Nos itaque, cum divina miseratione et singulari beneficio arcem nostram Smolenscensem ${ }^{26}$ caeterasque provincias nostras iniquissime ab hoste Mosco sub tempus pactorum, primum quidem divi Sigismundi Tertii domini, parentis nostri desideratissimi ${ }^{27}$, expugnatione, recenter vero nostra ad Smolenscum expeditione felice, utriusque nostrum periculo recuperatas, Magno Ducatu Lituaniae restituerimus. Postquam pro situ et patientia locorum res componere et stabilire licuit, omni quoque, qua licet, animi gratitudine divini erga nos beneficii memoriam respicere atque venerari et imposterum testari publice constituimus. Muneri enim vicissim

23 Wradysław IV Waza, król polski (1632-1648).

26 Smolensk, zob. przyp. 12.

27 zygmunt III Waza, zob. przyp. 11. 
debitoque nostro consentaneum existimavimus, non prius alicubi ditiones nostras, quam Dei optimi, maximi honorem, veraeque religionis integritatem incipere. Nam in his una veraque felicitatis omnis vis et salubritas constat, quippe cum quibus Deus ipse in sincera sui adoratione ad actionem rerumque omnum auspicia et successus praesentis et faventis Numinis benevolentia adest.

Quamobrem, ut sacris honos et sinceritas' sua illic restituatur, ubi provincia Magno Ducatui Lituaniae principique suo restituta est, eam non a barbarae tantum crudelitatis iugo, sed a corrupta religionis noxa vindicasse in gloria et felicitate nostra etiam ducere voluimus. Cuius rei cum maximum in eo sit momenturn, ut legitime et rite constituto regimine sacrorum munerum iura, sacraeque doctrinae progressus et caeremoniarum ritus disciplinaque ex ecclesiae et canonum praescripto instituantur et gubernentur.

Ideo, ut haec omnia censere perfecteque in Smolenscensi provincia instaurari possint, neve illa posthac ad remoti pastoris curam et longincua praesidia exire, aut distrahi cogatur, laudatis maiorum nostrorum aliorumque principum piorum vestigiis insistentes, singularem dioecesim et episcopatum in praefatis provinciis, sub titulo et appellatione Smolenscensis, per serenissimum olim dominum parentem nostrum fundatum ac erectum, et proprium et peculiarem episcopum, nempe rev. Petrum Parczewski, metropolitano tamen et primati Regni subordinatum, dandum et assignandum duximus, prout quidem de Sanctae Sedis Apostolicae consensu et approbatione minime ambigentes, praesentibus approbamus, confirmamus et ratificamus piamque mentem et fundationem divi parentis nostri ad excutionem deducimus. Cui quidem episcopo noderno et pro tempore existenti regimen totius cleri, in ducatibus Smolenscensi et Severiensi existentis, iuxta iura canonica et consuetudines S.R.E. longo usu probatas, in perpetuum committimus. Et inprimis antiquissimam ecclesiam muratam tituli Annuntiatae Virginis IMariae, modo quidem desertam, sed olim a preadecessoribus nostris piae extructam, intra muros Smolenscenses, in monte $\mathrm{Przecisciessoka}$ alias $\mathrm{Dziedz} i \mathrm{niec}$ sitam, pro ecclesia cathedrali assignamus, ibidemque in monte pro residentia episcopali domum veterem muratam, nominatae ecclesiae contiquuam, cum sufficienti pro aula et pomario episcopalibus capacitate, areas quoque pro domibus praelatorum, canonicorum aliorumque presbiterorum a civitate Smolenscensi, eiusdem montis partem occupante, dislimitatas assignamus, ita tamen ut area sive domus cuiusque praelati et canonici intra longitudinem octuaginta, latitudinem vero quadraginta ulnarum non excedat, aream vero pro horto episcopali extra muros cum iusta capacitate concedimus. Item alteram ecclesiam muratam tituli $S$. Spiritus, similiter a praedecessoribus nostris extructam, ad praesens desertam, extra muros Smolenscenses ad Boristenem ${ }^{23}$ sitam, ubi INoschus erat castrametatus, cum caemeterio eandem ecclesiam circumdante, assignamus. Quam ecclesiam suprafatus nominatus episcopus Smolenscensis restaurare divinaque missae officia diebus festis iuxta arbitrium et dispositionem propriam celebrari procurabit.

Nundinas demum mercatoribus ac civibus circa eandem ecclesiam fier,i mercimoniaque libere exercere pro festo Pentecostes per septimanam ex vi huius privilegii nostri concedimus. Porro, ut episcopi Smolenscenses, pro tempore existentes, pro statu suo praesulari honesti et convenienter vivere possint, eidem episcopatui Smolenscensi ad usum fructum episcoporum Smolenscensium bona certa in ditione palitinatus Smolenscensis Malachoviensi ${ }^{29}$ sita, $\mathrm{Vujsock}$ nuncupata $29 \mathrm{a}$, per geometram nostrum in quadringentos laneos redacta. Alia item bona in ditione

as Bortstenes, zob. przyp. 15 .

2o Malachow, zob. przyp. 16.

${ }^{29}$ a Zob. przyp. 17. 
eiusdem palatinatus Katinensia ${ }^{30}$ et Bereznia ${ }^{30 a}$ sita, vetus castellum Ols z a n k o $\mathrm{o}^{31}$ cum agris contiguuis et pratis in quadringentos itidem laneos redacta et dislimitata, designamus, sigillatim vero in ditione eiusdem palatinatus Smolerscensis Dolhomoscense ${ }^{32}$ laneos ducentos per succamerarium nostrum, seu camerarios designandos et dislimitandos. In capitaneatu praeterea nostro Bielscensi ${ }^{33}$ laneos quingentos per eosdem camerarios nostros ad hoc deputatos seu succamemarium designandos et dislimitandos. Denique in capitaneatu nostro Starodubensi ${ }^{34}$ vetus castellum, Popova Gor $a^{35}$ nuncupatum, mille laneos agrorum et silvarum propius adiacentium per geometram nostrum iuratum una cum commissariis nostris ordinatum ac limitatum in perpetuum applicamus et irrevocabiliter in aevum appropriamus.

Porro ut cultus divini, quem nos apprime desideramus, gravior sit maiestas et amplitudo, ad eandem ecclesiam cathedralem Smolenscensem sex praelatos, praepositum videlicet, decanum, archidiaconum, custodem, scholasticum et cantorem, canonicos insuper duodecim, eos vero tantum nobili ortos genere, veletram doctores, in perpetuum instituimus et designamus. Episcopus in id maxime incumbet, ut numerus adequatus canonicorum, ut scilicet beneficia specificata longo intervallo temporis vacent, successive expleatur; pro quorum habitatione et vicariorum (quos canonici quilibet suum habere tenebuntur), tum scholae et musicorum ecclesiasticorum provisione in ditione palatinatus Smolenscensis Boyhorodensi ${ }^{36}$ laneos mille per geometram nostrum iuratum, assistentibus commissariis, designatos, mensuratos et dislimitatos assignamus et in perpetuum capitulo Smolenscensi incorporamus. Ita tamen, ut ex laneis praedictis centum lanei cedant praeposito Smolenscensi, octuaginta lanei decano, archidiacono octuaginta, custodi octuaginta, scholastıco sexaginta, cantorı sexaginta, caeteris vero duodecim canonicıs lanei quingenti, cantoribus et custodibus ecclesiasticis lanei quadraginta. Insuper toto capitulo Smolenscensi silvae laneos centum in eadem ditione Boyhorodensi; in capitaneatu vero Bielscensi laneos quingentos per succamerarium nostrum, seu commissarios nostros specialiter ad id deputatos, designandos, per geometram vero nostrum uratum limitandos perpetuis temporibus impartimur. Denique eldem capitulo Smolenscensi ad maiorem eorum commoditatem et residendi assiduitatem et studium cathedralis ecclesiae in eis exitandum pro hortis et praediolis praelatorum et canonicorum post agros, sive pascua clvitatis nostrae Smolenscensis, laneos centum per succamerarum, seu commissarios notros designandos et limitandos, perenniter, donamus, eaque omnia bona suprascripta tam episcopatui, cuam capitulo Smolenscensi a nobis in perpetuum donata et incorporata, libertatibus et immunitatibus S.R.E. adscribimus, ita tamen, ut iuri quoque communi Magni Ducatus Lituaniae, iudiciisque ordinariis, in tribunali vero iudicio composito subsint, prout aliarum quoque ecclesıarum in Magno Ducatu Lituaniae existentium possesiones subsunt, iuribus tamen S.R.E. salvis. Caeterum proventus bonorum capituli, qui cuique sit pendendum, aut quae bona cuique praelatorum et canonicorum sint tradenda, primus episcopus Smolenscensis ex consilio capituli ordinabit et decer net.

Collationem porro et iuspatronatus, tam episcopatus Smolenscensis, quam et praelaturarum et canonicatuum Smolenscensium, nobismetipsis et successoribus

\footnotetext{
3o Katyń, zob. przyp. $1 \overrightarrow{0}$.

s"a Berezina, zob. przyp. $18 a$.

31 Olszanko, zob. przyp. 19.

32 Dorohobuz, zob. przyp. 20.

33 Biata, zob. przyp. 21.

34 Starodub, zob. przyp. 22.

s Popowa Góra, zob. przyp. $22 \alpha$.

as Lojhorod, zob. przyp. 23.
} 
nostris, serenissimis regibus Poloniae et magnis ducibus Lituaniae reservamus. Ut nihilominus episcopus quoque Smolenscensis maiori apud clerum authoritate valeat et studiosius observetur, excipimus quatuor anni menses, februarium, aprilem, octobrem et docembrem, quibus, si quem pralatorum aut canonicorum Smolenscensium de vita excedere contigerit, vacantes sub nominatis quatuor mensibus praelaturas et canonias, ipsemet episcopus Smolenscensis clericis integritate et doctrina conspiculs, et de Sanctae Ecclesiae bene meritis, nostro et successorum nostrorum iurispatronatu non obstante, pro libitu et voluntate sua, praesentis privilegii nostri vigore, conferre valebit; eaque designatis quatuor mensibus praerogativa, a nobis benigne concessa, episcopi Smolenscenses in perpetuum utentur et gaudebunt. Caeterum bona praefata omnia, tam episcopi Smolenscensi in perpetuum, unus post alium sua, quam praelati et canonici itidem sua, sibi a nobis data, et in perpetuum donata, tam domus in civitate Smolenscensi, quam alias quoque possesiones terrestres, modo suprascriptas, linitatas et limitandas, omnibus subditis praesentibus et imposterum futuris, eorumque censibus et regimine cum agris, pratis, silvis, nemoribus, fluviis, lacubus, stagnis, piscationibus, venationibus, melificiis, caeterisque omnibus usibus, fructibus et quibuscunque redditibus, intra limites superius designatos contentis, et in posterum inveniendis, pacifice tenebunt, possidebunt, et supra praescriptum S.R.E. perpetuis temporibus uti fruentur, omnibusque praerogativis, honoribus et praeeminentiis, episcopi vero Smolenscenses loco et in senatu nostro, ex consensu publico designando, potientur et gaudebunt.

Demum obligamus eosdem, ut circa ecclesiam cathedralem Smolenscensem residere, pro nobis et serenissimis successoribus nostris ac tota Republica nostra Deum optimum, maximum exorare teneantur, omnimodam deinde devotionem ac caeremonias iuxta ordinem, consuetudinem, dispisitionem ecclesiae cathedralis Vilnensis ${ }^{37}$, matutinaque et horas canonicas, tam ante meridianas, quam post meridianas, prout disponet cum capitulo episcopus, cantare tenebuntur, divinumque honorem omni conatu et studio promovere obligabuntur. Praeterea in perpetuum, ex vi huius privilegii nostri, episcopi Smolenscenses annuatim intuitu victoriae per serenissimum divae memoriae dominum parentem nostrum desideratissimum super hoste Moscho obtentae pro festo s. Antonii de Padua, die quo divina miseratione Smolenscum ab hoste est receptum, perennem gratiarum actionem et vivam praeclari divini beneficii memoriam submissi providere, processiones et supplicationes publicas instituere, et quantas potest humana infirmitas gratias referre. Insuper quovis anni mense semel, ut minimum in eiusdem beneficii memoriam tenebuntur episcopi Smolenscenses per se, sive per aliquem praelatorum, gratissimo et solemni missae officio sacrosanctam et vivificam hostiam supremo Trinoque Numini parentare. Intuito vero victorlae felicibus auspiciis nostris super eodem Moscho obtentae tenebuntur, pro festo s. Michaelis Archangeli, nec non s. Matthiae Apostoli ${ }^{38}$ itidem per se, sive per praelatum ad id destinatum, supplicationes, uti supra specificatae sunt, quotannis solemniter instituere, et praecari, ut eas provinsias, quas nobis et Reipublicae nostrae benigne restituit, clementer tueri, et manu sua potenti dignetur ab hoste defendere verumque et inviolatum sui in eis cultum quam diutissime conservare.

Quae quidem omnia vim perpetuitatis obtinere volentes, praesentes manu nostra subscripsimus sigilloque nostro Magni Ducatus Lituaniae obsignari mandavimus. Datum Varsaviae die 28 mensis aprilis anno Domini 1635, regnorum nostrorum Poloniae et Sueciae tertio anno.

${ }^{3 T}$ Wilno, stolica Litwy, w latach 1380-1795, 1918-1939 nalezato do Polski.

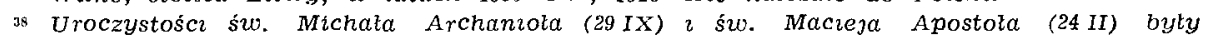
rocznıcamı zwyciestw Wtadystawa IV w wojne z Rosja. 